\title{
El manejo del discurso educativo en el aula
}

\author{
Estela Terán Parral ${ }^{*}$
}

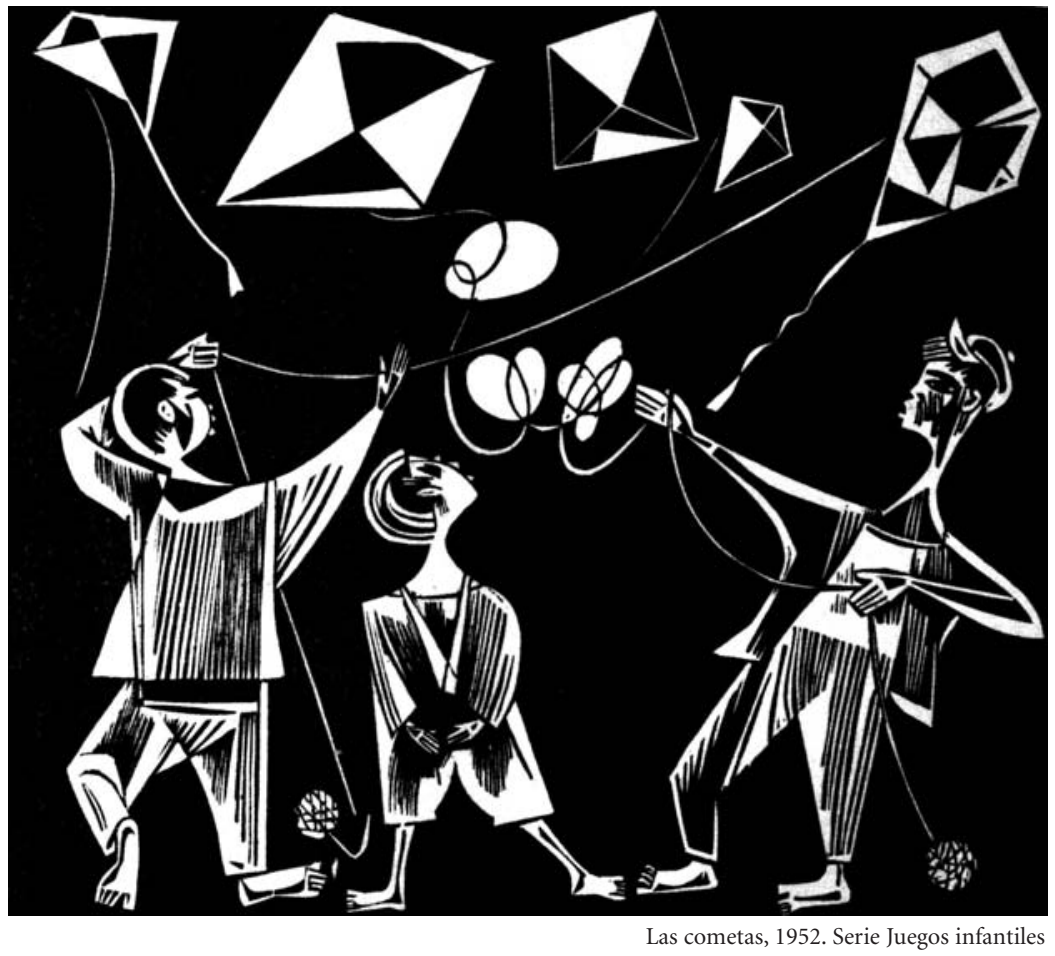

\section{Introducción}

A través de mi vida estudiantil y luego como docente, he comprobado la repercusión que tienen palabras, mensajes y vivencias, que, día a día, se fraguan en nuestras aulas. Es así que continúo cuestionándome el rumbo de la educación, tanto como su sentido en la formación de seres humanos. He sido obsecuente al célebre Einstein que dice, 'la cuestión es no parar de cuestionar. Por ello a través de esta presentación deseo comprender la vida y mi camino como una permanente indagación, una búsqueda de certezas en medio de incertidumbres. Estos son pasos ontológicos de mi vocación para encontrarme a mí misma y la procura de una práctica de lo deontológico, siempre errante en mi conciencia. "Porque la elección ética está en todas partes y en todos los momentos". ${ }^{1}$

El manejo del discurso educativo en el aula, es un tema que cada vez adquiere mayor relevancia por ser una práctica que permite al edu-

Datos de la autora: Licenciada en Ciencias de la Educación (UPS). Este artículo fue presentado en el Tercer Seminario de graduación de la Carrera de Pedagogía (febrero 2007). 
cando su desarrollo multidimensional. Este manejo, integrado a las múltiples disciplinas en las que se ha de formar el estudiante, contribuye a su crecimiento integral. La claridad de este objetivo, así como la habilidad docente, facilitan un proceso educativo para construir aprendizajes significativos y a la vez profundizar en la riqueza de los conocimientos.

Por este motivo, es importante valernos del marco teórico pertinente, e incluir el espíritu filosófico que impulsa esta temática, así como los principios científicos en el campo de la psicología y de la pedagogía, que dan a luz los criterios básicos para madurar este estudio. A continuación, se compone una visión palmaria del escenario educativo y su discurso, y luego se detalla cada una de las dimensiones que éste comprende. Finalmente, y con auxilio de palabras ilustradas de los eruditos y científicos convidados a compartir este pequeño tramo, este texto despliega una dimensión con sentido meta-físico que aspira, por un lado, reivindicar el rol docente, y por otro reflexionar en lo genuino y realmente trascendente de la divina misión que Dios encarga al maestro; como el artista apasionado que esculpe con goce singular, su pieza escultórica.

Para explicar este ensayo, reproduzco las palabras de Theodore Roszack:

"Demasiada parafernalia, al igual que demasiada burocracia, sólo sirven para inhibir el flujo natural (de enseñar y aprender). El libre diálogo humano, deambulando por donde permita la agilidad mental, sigue estando en el centro de la educación. Si el profesorado carece del tiempo, del aliciente o del ingenio necesarios para propiciarlo; o si el alumno está demasiado desmoralizado, aburrido o distraído, como para dedicar la suficiente atención que su profesor o profesora requiere de él, ése es el problema educativo que hay que resolver, y hay que resolverlo desde dentro de la experiencia, tanto del profesorado como del alumnado".2

Afirmo con Neil Postman, que la naturaleza de este proceso no es técnica sino metafísica. Por lo que es necesario ir al meollo, al alma, de esta problemática y dejar a un lado, por esta vez, las in- genierías del aprendizaje que nos podrían distraer del objetivo. Al respecto, oigamos lo que dice el Eclesiastés: "Porque donde hay mucha sabiduría, hay mucha molestia, y quien aumenta la ciencia, aumenta el dolor," ${ }^{3}$ sin que esto signifique omitir la dimensión técnica que es indispensable en el manejo del discurso educativo, o que constituya una mera improvisación. Comprendámoslo así, junto a Juan Pablo II, "La ciencia puede purificar la religión del error y la superstición. La religión puede purificar la ciencia de la idolatría y de los falsos dogmas". ${ }^{4}$ La idea promovida en este texto, es justamente, que tratados diferentes e igualmente indispensables, puedan convivir antes que repelerse, pues estoy segura, que lo distinto nos enriquece, expande la visión y la similitud nos acerca más, nos llena de esperanza. Por este motivo, pasemos a configurar el parámetro filosófico que sea capaz de sustentar el discurso educativo.

\section{Espíritu filosófico del discurso educativo}

Todo lo que involucra el ideal humano apunta al principio del Humanismo, corriente filosófica que se originó en las artes y en las letras, como exaltación de las cualidades humanas. Toma y valora la creación que sale de la mente y del espíritu. Este pensamiento considera al hombre como el alfa y el omega de nuestras sociedades. La educación que busca el perfeccionamiento del individuo es Humanista, pues su misión es cultivar la ciencia educativa como un arte genuino. Es así que toda actividad formadora, encuentra perfecta combinación y empatía con esta base filosófica, como eje para el desarrollo integral de la persona. A su vez, el Humanismo se ve consolidado mediante principios democráticos e igualitarios que buscan un compromiso en la comunidad, gracias al trabajo cooperativo para una transformación social, es decir humana. El Humanismo también encuentra su vigencia en valores como el bien común, la bondad que expresa solidaridad y la apología de lo estético. Sin embargo, el valor fundamental es la libertad dentro de una acepción fidedigna de la pa- 
labra; y también debe existir especial atención al respeto, la alteridad y la responsabilidad, lo que infiere vivir dentro de ellos, coherentemente.

De todas formas como nada es perfecto y, sobre todo para evitar riesgos de tipo dogmático, es necesario orientar este esquema desde enfoques teóricos y prácticos de otras disciplinas científicas, que revelen una visión ecléctica para conjugarse con el fundamento de base, que acaba de ser presentado. Por lo tanto la Hermenéutica a pesar de ser muy antigua, específicamente en la materia que compromete este estudio, resulta útil, pues contempla el lenguaje y la construcción simbólica en distintos niveles de abstracción. Igualmente lo hace la Semiótica. Y es que la explicación del mundo va más allá de las descripciones lingüísticas que se puedan hacer de él. Es posible de-codificar palabras, ideas y pensamientos, lo que indica el camino hacia el meta-lenguaje, "lenguaje sobre el lenguaje"5 como juicio que vigoriza la educación. Así mismo, la Etimología desentraña desde la raíz, la significación de las palabras. Por su parte, la Deontología resguardará el aspecto ético del discurso educativo en el aula. Finalmente, para no diluir este trabajo en inútiles divagaciones, hay que permitir a las ciencias, al lenguaje, al arte, cobrar sentido verdadero y vida real, y conocer mejor los principios psicopedagógicos del objetivo del discurso, el educando.

\section{Principios psicopedagógicos del discurso educativo}

Sin duda el discurso educativo debe basarse en quiénes son los que reciben el mismo. ¿Son niños?, ¿adolescentes?, ¿cuál es su contexto social y cultural? El desarrollo evolutivo del niño que plantea Piaget es una acertada directriz para comprender hacia donde va el discurso. La dimensión instructiva del discurso, exige los procesos de organización mental de los conocimientos en esquemas de construcción; luego la adaptación dentro de la cual la persona procura asi- milar lo nuevo, a lo que ya sabía y por último acomodarlo para formar y transformar los esquemas mentales. Cuando todos estos procesos se cumplen satisfactoriamente, surge el equilibrio que no es sino el balance de esta suficiencia. Las etapas de desarrollo cognoscitivo que señala Piaget (sensoriomotriz, preoperacional, opera-

\section{Este pensamiento considera al} hombre como el alfa y el omega de nuestras sociedades. La educación que busca el perfeccionamiento del individuo es Humanista, pues su misión es cultivar la ciencia educativa como un arte genuino.

cional concreta y operacional formal) trazan la secuenciación de los contenidos y las actividades que propician la superación de cada una de ellas. Así, el juego simbólico en la etapa preoperacional, favorece la función semiótica, que permite a los niños utilizar símbolos, lenguaje, imágenes y gestos que 'representan' algo. (Ejemplo, una escoba se convierte en un caballo). En esta etapa el lenguaje es el mayor protagonista que abre paso a las operaciones concretas y más tarde a las operaciones formales que requieren de un pensamiento lógico, abstracto y analítico.

Pero el discurso educativo encuentra su mayor asidero en el psicólogo ruso, Lev Vigotsky. Él propuso ideas alternativas a partir de la investigación piageteana, pues otorga una fuerza y agudeza especiales al lenguaje y al entorno inmediato que interactúa con el educando, lo que da una perspectiva cultural a la evolución psicopedagógica. Sucede así que un niño pobre vendedor de dulces, sin haber asistido a la escuela, conoce las operaciones matemáticas básicas. El 'discurso privado' de Vigotsky es una plática (audible) interna del niño, que guía su aprendizaje tanto conductual como intelectual. A medida que éste avanza, se convierte en murmullos y luego pronuncia palabras claves que dirigen su pensa- 
miento, para más tarde, desaparecer. Sin embargo, el adulto se vale de este 'pensar en voz alta' para recordar, relacionar, alentarse o también guiarse. El 'aprendizaje asistido' del que habla el autor, requiere la asistencia de un adulto o docente. Se crea un "andamiaje"6 que da soporte al aprender independiente del alumno; por ejemplo, en el caso de realizar preguntas, éstas generan conceptos y categorizaciones. Esta asistencia es mayor, cuando surgen dificultades sobre todo en la "zona del desarrollo proximal"7 en donde el niño puede resolver los problemas con ayuda de su tutor. Por lo tanto, este 'aprendizaje asistido' posee un vínculo muy estrecho con el 'discurso educativo' en el que ahora cabe profundizar.

\section{El discurso educativo}

El discurso educativo es una serie de enunciados principalmente verbales, aunque también se incluyen los no verbales y los paraverbales, que son concatenados y congruentes entre sí, y que se ponen a la disposición de la formación del alumno. El discurso facilita poco a poco el cumplimiento de metas que satisfacen una programación de aprendizajes de diferente clase. Éstos son manejados desde una perspectiva pluridimensional porque sus componentes son completamente heterogéneos, lo que si bien hace complejo su desarrollo, produce enriquecimiento formativo. Como queda dicho, los men- sajes verbales son aquellas expresiones totalmente claras y comprensibles. Los no verbales, son los mensajes latentes que difícilmente pueden ser identificados, pues carecen de la expresión verbal. Por último los paraverbales son los mensajes intermedios que se encuentran semiexplícitos, semiocultos.

Reconocer el nivel de madurez, la edad cronológica, las necesidades, los intereses, las circunstancias culturales y el ritmo de aprendizaje tanto individual como grupal, es un buen punto de partida. El discurso educativo comprende la comunicación recíproca que se produce entre emisores y receptores.

De esta dinámica, se desprende el lenguaje como factor mediador. El maestro lo utiliza como "principal instrumento intelectual" 8 , ya que el entorno se explica a través de un mapa lingüístico. El autor Neil Postman, lamenta que el estudio del lenguaje no constituya el eje central tanto en la formación docente como en la dicente, porque, a más de ser indispensable, cada materia posee su retórica característica. A pesar de que la mayoría de aprendizajes radican en el campo lingüístico, el maestro actual es huérfano de esta destreza. Como protección, Postman indica que “...para reconocer el error, para defenderse de la seducción de la elocuencia, hace falta tener algún conocimiento del metalenguaje" 9 , como lo es el meta-conocimiento que concierne a la estrategia del aprendizaje. Y Paulo Freire acoge este aspecto, con el siguiente dictamen: "Generalmente, 
cuando se critica nuestra educación, nuestro apego a la palabra hueca, a la verbosidad, se dice que su pecado es ser 'teórica'. Se identifica así, absurdamente, teoría con verbosidad ${ }^{10}$; y diría yo, se confunden estos términos, y continúa; "Es verbosidad, es palabrería, es 'sonora', es asistencialista $^{11}$ no comunica; hace comunicados, cosas bien diferentes". ${ }^{12}$ Este fenómeno se sintetiza grandemente con el concepto que Heidegger entrega: 'palabra verdadera, palabra falsa'. Postman me ha exhortado a liberarme de la tiranía de las definiciones y la manera de hacerlo es crear conceptos alternativos; porque en el 'poder' que ostenta el maestro, está implícito el imponer definiciones; y estimo que lastimosamente cae en las 'etiquetas' a las respuestas del alumno, como 'correcto o incorrecto'; o 'verdadero o falso'.

El educador debe manejar su discurso, también a la luz del amor. "El lenguaje del amor busca los sonidos suaves y las palabras que se arraigan en la historia de la humanidad, los conceptos profundos y universales, aquellos que recibieron su principal brillo en las obras de los poetas". ${ }^{13}$ La poesía, las historias, las novelas, la música, el arte, de hecho son persuasivos lazos con los estudiantes. Según Mallarmé, la poesía no se hace con ideas sino con palabras, como la seducción. Parafraseando al autor Álex Grijelmo, las palabras que en los diccionarios aparecen tan simétricas, silábicas, sintácticas y que guardan estrictamente los significados idiomáticos, no son sino la puerta de entrada a un mundo sensorial y de reminiscencias aletargadas que cobran vida, con sólo pronunciarlas. Regularmente las palabras cumplen su función de persuasión y disuasión cuando van de la inteligencia del emisor, hacia la inteligencia del receptor. Pero es la seducción la que hace que éstas partan de las emociones del emisor hacia las de su receptor.

Sin duda las palabras son también las semillas de nuestra herencia cultural. Por ello digo que la literatura es la memoria de la humanidad y recopiladora universal, que refleja la necesidad de trascendencia de los pueblos; y los profesores tienen la obligación de escoger literatura de cali- dad. Entre las figuras literarias, la metáfora suele embellecer las expresiones, por eso es un recurso válido, afirma Postman, para explicar nuestra propia cotidianidad, que perfile imágenes múltiples de un mismo panorama.

Lamentablemente, el posible encanto literario se rompe gracias a los libros de texto, "enemigos de la educación", 14 donde todo luce como un producto terminado, donde sólo hay una manera de aprender. Por ejemplo; la historia ecuatoriana nos presenta héroes irreales, en situaciones ficticias, sin lugar a discusión; lo que construye un aprendizaje trivial y dogmático. Tanto es así, que Postman se vale del antiguo refrán, "El niño entra en la escuela como un signo de interrogación y sale de ella como un punto", 15 cuando lo que correspondería, según este boceto, es que se marche cargado de interrogantes. De todos modos, se podría hacer un análisis positivo y pensar que los textos son pretextos para de allí partir en busca de los conocimientos y de las verdades, y así deberían ser usados por los profesores.

Según Meirieu, la verbalización en el aula juega un papel motor porque hace pensar y, como dice Aebli, el pensar es actuar. Y al sentir de Sócrates, "cuando la mente piensa, se habla a sí misma". ${ }^{16}$ Este es un diálogo interno comentado ya por Vigotsky, porque el "lenguaje proporciona organización a nuestro sentido moral". ${ }^{17} \mathrm{El}$ maestro recurre a la mayéutica que consiste en formular preguntas hábiles, dirigidas a la reflexión del alumno, para encaminarlo hacia un aprendizaje significativo que evita un razonamiento parcial. Así, se produce la interiorización del conocimiento, proyectado en las acciones efectivas. Habrá momentos en que sea necesario devolver la pregunta a los estudiantes, diciendo: 'respóndanse ustedes mismos'. De este modo, es muy provechoso problematizar situaciones para dar significación a las expresiones en donde lenguaje y pensamiento sean correctamente conjugados. Por ello, la necesidad de un dominio tanto oral como escrito.

Dentro del aula y como parte del discurso, el refuerzo positivo interviene de forma cons- 
tante y oportuna. "El refuerzo más efectivo en el proceso del aprendizaje es aquel que sigue a la acción con una mínima demora... el refuerzo inmediato". 18 Dilatar el tiempo, minimiza su efecto. Recurrir a la sanción, que para Meirieu es 'escoria educativa' e 'instrumento de homogeneización', es pretender moldear y amaestrar a los educandos, 'cortarlos con la misma tijera', y así morir a la heterogeneidad; "la uniformidad es enemiga tanto de la vitalidad como de la excelencia". ${ }^{19}$ Ahora bien, quiero pensar con optimismo que un alumno motivado no necesitaría sanción alguna. Sin embargo, el mismo autor francés, pondera que una sanción oportuna, con razón contundente y convicción de un obrar ético, es legítima.

En resumen, el discurso educativo es muy extenso pues está presente de principio a fin, en todas las aulas, en todo aspecto; de ahí que es fundamental conocer su dimensionalidad, a fin de obtener una percepción inteligible y poder identificar cada una de las áreas de actuación docente.

\section{Dimensionalidad del discurso educativo}

La heterogeneidad y complejidad que fueron anotadas, corresponden a la multidimensionalidad del discurso educativo, divididas en cinco dimensiones distintas por sus particularidades inherentes.

\section{Dimensión instructiva}

Se refiere a la formación académica, que son las asignaturas y contenidos científicos. Tradicionalmente la instrucción ha jugado siempre el papel primordial, y se ha descuidado los otros componentes discursivos. Posee un carácter expositivo en el que predomina la objetividad. Sus construcciones gramaticales son complejas con un lenguaje riguroso pero claro. Promueve la función representativa del lenguaje. Proliferan con- ceptos, datos y términos tanto técnicos como científicos.

Paulo Freire ve la misión del maestro como coordinador que busca la participación y el interés para develar aquello que produce enriquecimiento mutuo. Se hace uno más entre los demás, al encuentro de ese espacio de "diálogo vivo y creador en el cual todos saben algo o ignoran algo y buscan juntos, saber más". ${ }^{20}$ En este caso el maestro también guarda silencio, escucha con respeto, con sencillez, y se solidariza con la lectura que su alumno da de su entorno. Así, personalmente, procuraría acatar a Freire, en su Pedagogía de la Serenidad.

Por otro lado, el educando es ese ser imperfecto y maravilloso a la vez, que habita en cada uno de nosotros, aunque creamos saberlo todo por nuestra edad y experiencia. Hablamos aquí de 'educabilidad', como Meirieu lo define, porque todos podemos perfeccionarnos, no para ser infalibles, sino para poder emanciparnos. “¿Qué más se puede esperar de la educación que este descubrir la plenitud individual que se siente cuando uno se habita a sí mismo, cuando la voluntad coincide con el acto y el sujeto puede ser el verdadero autor de sí mismo y decir "yo"?"21 Pues bien, ese 'yo', al entender de Marcel es un individuo 'situado y fechado, creador de cultura'.

Estamos así, 'insertos'22 en esta co-creación, porque estamos no 'en', sino 'con' el mundo, como asegura Freire, porque a diferencia del animal que se acomoda y se ajusta a su entorno, el hombre se integra para convertirse en un sujeto consciente y activo. Esta "conciencia transitiva" 23 que entiende el estado ideal del educando, en la etapa más elevada de la evolución de la conciencia, es crítica, participativa, democrática y muchas veces radical y rebelde. Obedece a causas reales y no míticas, por lo tanto es libre. Atiende al presente, incorpora el pasado, para proyectarse al futuro. Se aventura a buscar nuevos caminos y tiene en cuenta su historicidad que justifica esa facultad.

Meirieu se refiere al educando, con profundo respeto, como 'el Otro'. Su palabra docta lo con- 
vierte en educador de educadores, que escribe para educadores-educandos, aunque sus obras cubren un amplio espectro de lo humano. Este 'Otro', posee la "...curiosidad intelectual (como) fuente inagotable de descubrimientos y alegrías...".24 Porque, además, como lo entiende Freire: "Frente a una sociedad dinámica en transición, no admitimos una educación que lleve al hombre a posiciones quietistas, sino aquellas que lo lleven a procurar la verdad en común, 'oyendo, preguntando, investigando'." ${ }^{25}$ Así, el alumno se educa, dominado por la duda, se expresa -como necesidad ontológica- desinhibidamente, sin temor a ningún ridículo y sin la presión de criterios impuestos.

Mucho se ha reflexionado sobre la

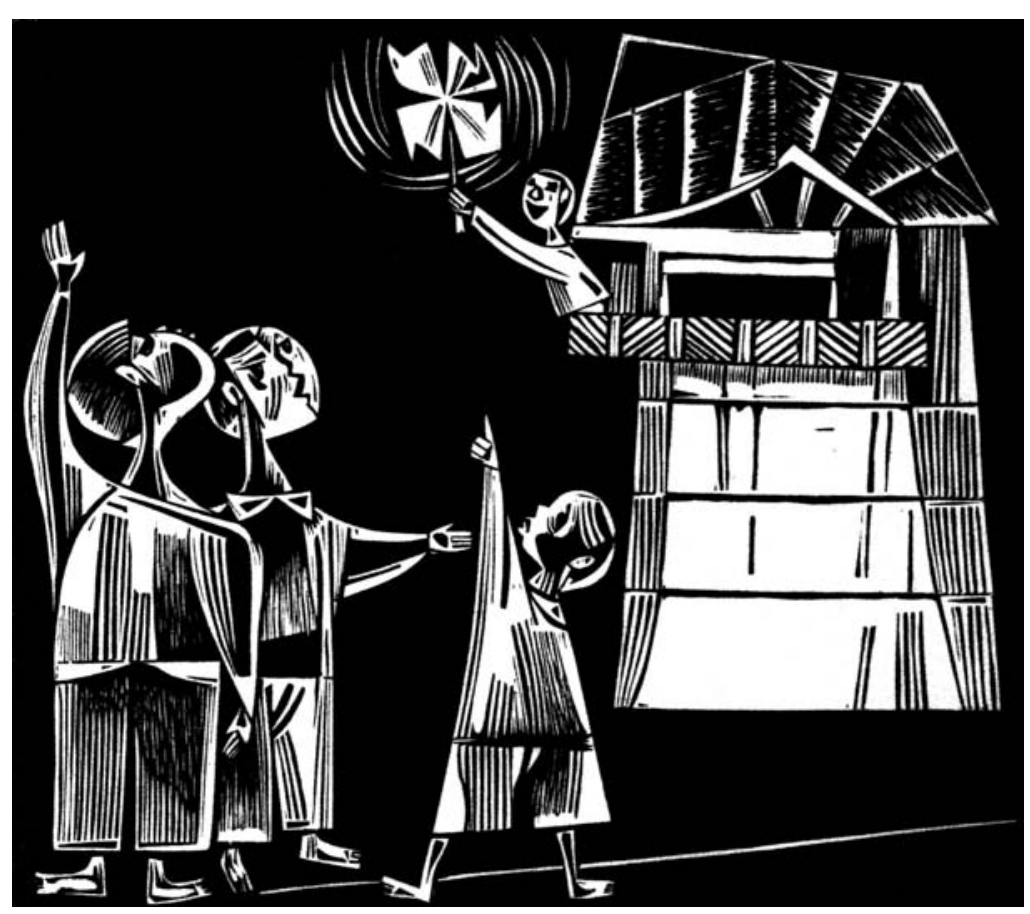

La rosa de los vientos, 1952. Serie Juegos infantiles teoría de Piaget respecto al desarrollo evolutivo del infante, que ve al niño como una “...tábula rasa sobre la que se imprimen progresivamente las impresiones suministradas por los sentidos"; 26 éstas forman un "cuadro intelectual" 27 causado por una "impresión sensible" 28 como lo reconocen Comenio y Pestalozzi; porque el espíritu percibe las impresiones que son elaboradas por el pensamiento, para luego hacer posible su evocación interior. Ardila cree que la máxima motivación es cuando los trabajos son, ni tan fáciles, ni tan difíciles, cuando el sujeto elige el tema, cuando participa, explora y propone variaciones.

Y con respecto a los contenidos que estamos enseñando en nuestras aulas, ¿ cuáles son las materias que proporcionan sentido a la educación? En el orden lingüístico, no conocemos el origen del alfabeto, la interpretación de los manuscritos ilustrados e incluso los inicios de la imprenta. Los filósofos griegos entendían el estudio como una armonía humana entre la aritmética, la astronomía, la música y la geometría; mientras que los sofistas contemplaban la gramática, la lógica, la retórica. Quizás deberíamos volver a ellas... como Postman propone, por ejemplo, volver al estudio de la

Arqueología porque ésta nos da un sentido de perspectiva planetaria; la Prehistoria y la Antropología, por su parte, nos ayudan a comprender mejor al ser humano y favorecen la asimilación de su dimensión global; la Astronomía, identifica al planeta como una nave espacial, en medio de tantas otras, a la que tenemos que salvar y cuidar, uniendo las fuerzas de la especie humana. De esta manera, es improductivo reducir las asignaturas a fechas, pesos, medidas, fórmulas, catálogos, límites geográficos, como históricamente se ha venido proyectando. Se ha disminuido el radio de acción, se ha sometido al pensamiento y se ha confinado al ser humano a esta pena.

En definitiva, Neil Postman proclama la necesidad de 'narrativas' 29 diferentes a las que nos hemos venido sujetando, a fin de dar un carácter de cosmovisión tanto planetaria como humana.

\section{Dimensión afectiva}

Así como la anterior dimensión descrita posee la mayor preponderancia, la afectiva ha 
sido limitada y poco cultivada. Como indicadores tenemos que este espacio se maneja a través del diálogo, lenguaje personal que expresa el estado de ánimo (anima=alma), por lo tanto es subjetiva y carece de homogeneidad. Sus vocablos coloquiales hacen valoraciones positivas, mucho más que críticas o negativas. Incluye también la comunicación no verbal como el contacto visual, la sonrisa, los gestos y así mismo, existe mayor proximidad física. Este tema se ha puesto en manos del departamento psicopedagógico de las instituciones, o en los dirigentes, a través de las horas de tutoría o asociación de clase. Lamentablemente no se ha dado a lo afectivo, el espacio predominante que requiere para satisfacer la importante misión a la que está llamado. Únicamente cuando los problemas personales comienzan a afectar el rendimiento escolar, se toman medidas resolutivas y ya no, de carácter preventivo. En todo caso, conozco algunos maestros de niveles más básicos, que se han esforzado por preguntar el estado de ánimo de sus alumnos, como un hábito, a fin de 'cotidianizar' la libre expresión, ajena de todo prejuicio y así destruir la absurda idiosincrasia de esconder los sentimientos.

Es más, entre los educadores, hay quienes de manera jocosa, definen su labor, como; 'psicólogo, terapeuta familiar, trabajador social, organizador político, consejero matrimonial, padre adoptivo, sacerdote e incluso en algunos medios, empleado doméstico'. Y es cierto. La escuela es la piedra de tope de todos los problemas sociales, como son la desintegración familiar, la pobreza, la alienación, la migración, etc., a los que debe responder, aún cuando no aporte soluciones definitivas. Es así que el educador se vuelve un paliativo que alivia tales circunstancias a fin de brindar el desfogue emocional que sus alumnos no tienen en casa, restaurar la estabilidad, y en definitiva hacer más llevadera su existencia. A esta actuación, Rubén Ardila la califica como "coordinación emocional".30

\section{Dimensión motivacional}

Es aquella dimensión del discurso que procura captar la mayor atención y entusiasmo. Se caracteriza por presentar contenidos nuevos a través de exposiciones y conversaciones, dentro de un contexto dinámico y versátil, así como animado y artístico, en situaciones heterogéneas. Utiliza ejemplos, jerarquías y coherencias. Se vale de la modulación de la voz, que se une a un lenguaje evocador, atrayente y sugerente, y que realiza pausas y silencios, para conciliar los elementos verbales y extraverbales. A mi modo de ver, las actividades extracurriculares han abierto esta área motivacional, a través de labores prácticas, el deporte, el teatro, la música, las artes plásticas, las letras, el periodismo, etc. Los contenidos, es decir la dimensión instructiva, podrían producir mejores resultados, si llevasen una mayor dosis motivacional, a fin de 'crear', aprendizajes significativos.

Pensando con Hans Aebli, hay que dar oportunidad a que los estudiantes se desempeñen con acciones reales como costura, carpintería, etc., y materialicen el producto de su dedicación, a fin de que sea constatado con orgullo y satisfacción por el alumno. Igualmente, desenvolverse con acciones ficticias de problemas prácticos, suscitan vivo interés. Sin duda, la autoestima se verá robustecida. En definitiva, el estudiante no puede ser ese 'banco' que recibe los 'depósitos del conocimiento', como Freire lo compara, sino que debe formar parte de la sociedad activamente, colaborando, produciendo, etc. Esta dimensión puede rescatar aficiones tempranamente, como un diagnóstico vocacional, e ir generando gozo y amor al trabajo.

\section{Dimensión Social}

Es aquella que lleva a la cohesión grupal a través de la exaltación de los valores de la convivencia humana, y así reconocer los comportamientos y los valores actitudinales. Los Consejos Estudiantiles, la labor social y las 'pastorales' de 
los colegios religiosos, son un claro ejemplo para esta dimensión. La dimensión social es humanizadora, persigue ideales personales y comunitarios, llama a una interacción a través de debates que generan la reflexión crítica de la realidad, la apreciación de lo cultural, de lo cívico; la argumentación coherente para la adhesión a ideas y personas. Se plantea frecuentemente la 'justicia' y la 'solidaridad' acompañadas de muchos términos abstractos. También recurre al léxico político que suele involucrar cargas ideológicas en sus mensajes, a través de exhortaciones con apreciaciones subjetivas, orientadas a la persuasión.

El método activo de Paulo Freire afirma categórico, "La educación es un acto de amor, por tanto, un acto de valor". ${ }^{31} \mathrm{Y}$ así, quien educa debe enfrentarse consigo mismo, debe encarar su realidad humana, su pasado, su historia; no a modo de autocrítica, sino de aceptación y, por vocación, entregarlo todo, sin reservas. Este "acto de valor" no pretende dar al educador el título de 'héroe', sino más bien recordarle que es un ser de carne y hueso, capaz de superar la duda, el miedo y cualquier otra amenaza, con coraje y por amor. Por este motivo, el maestro debe "retornar a su fuente que lo libera" 32 ; nutrirse del amor a la libertad que lo humaniza y lo aleja de la despiadada cosificación. Esto se consigue cuando el maestro, al decir de Jesús Arroyo en su libro "Paulo Freire, su ideología y método", está de cara al mundo real, a los que sufren, está a favor del cambio, para convertir nuestras sociedades en comunidades plenamente humanas que rechazan el pecado social e institucionalizado de la alienación.

El que se cree con derecho a imponer sus ideas hace imposible la comunicación porque imprime violencia y acaba con los principios de convivencia armónica. Donde aún exista división, enfrentamiento, opresión, el diálogo será el

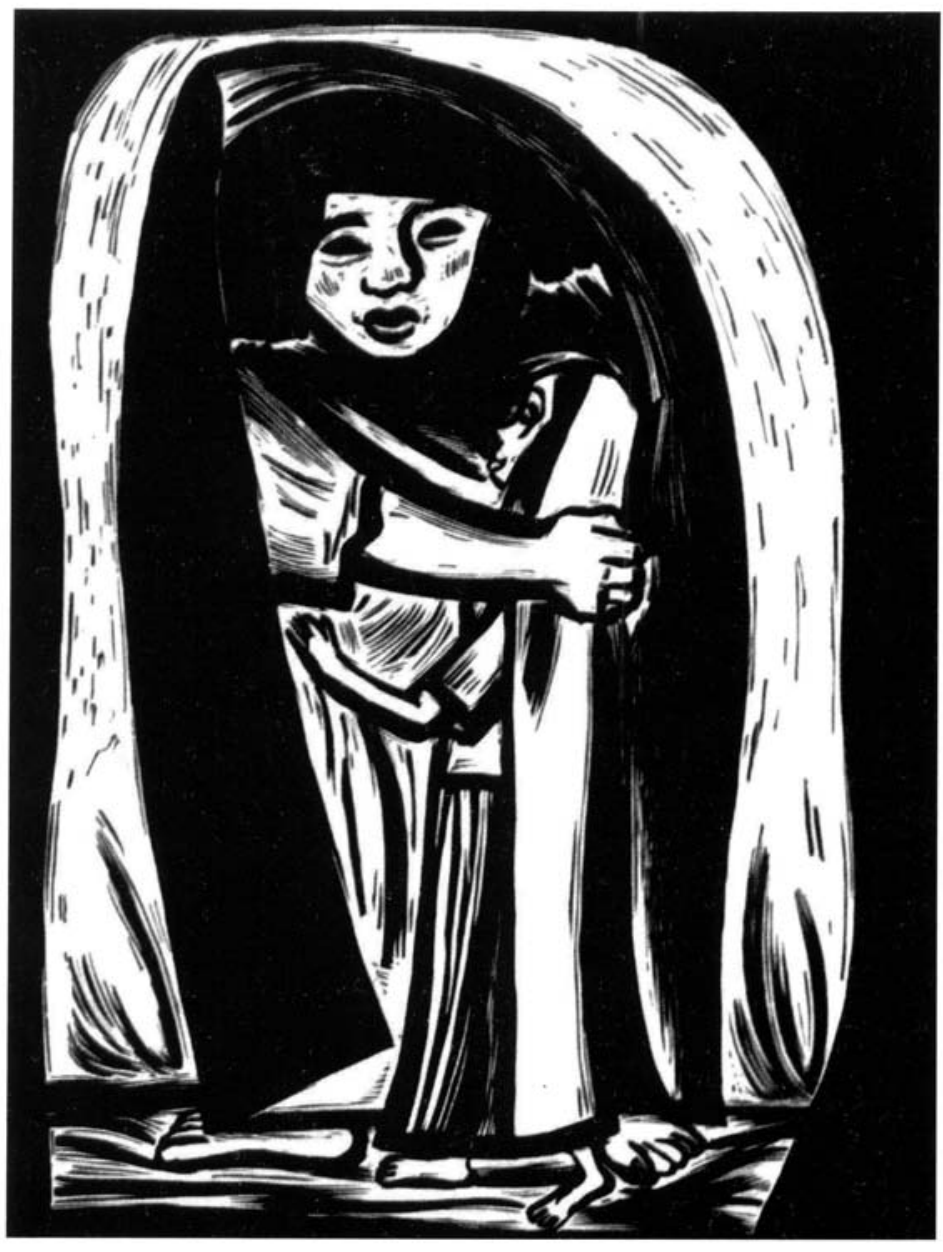

Madre abrazando a su hija. 1954

gran ausente, porque es incompatible con la intolerancia de la sociedad acorralada en este antidiálogo. Y en el camino sin-salida, los explotados de ahora que logran subir los peldaños de los anti-valores a los que fueron acostumbrados, comienzan a ser los nuevos 'opresores'33. Sino rompemos este círculo vicioso, con decisión, como una acción ética, no seremos capaces de educar verdaderamente. Otra vez escuchemos la voz de Paulo Freire: "No hay diálogo si no hay intensa fe en el hombre" 34 .

La práctica latinoamericana desde el colonialismo, ha mal-interpretado la educación como domesticación, lo que trae servilismo y crea una cultura del silencio porque hay miedo a la libertad, cuando en realidad "Los hombres no se 
hacen en el silencio, sino en la palabra, en el trabajo, en la acción, en la reflexión". 35 En efecto, el miedo es el ardid del cobarde y una vida así es peor que la muerte. Estimo que el miedo paraliza y rechaza el cambio. Sin innovación seremos castigados por la entropía, mientras que cuando haya cabida a las diferencias, a la diversidad que nos hace inteligentes, vamos a fortalecernos y a crecer. Ventajosamente, Paulo Freire también nos alienta con esta señal: "Solamente en la medida en que busco con esperanza, tengo el derecho de esperar". ${ }^{36}$ A esta consoladora alocución yo agregaría a la 'solidaridad' como el 'lait-motif para una acción eficaz dentro de esta dimensión.

El educando está llamado a involucrarse, así como 'insertarse', para tener derecho de poner en duda las opiniones de su propio profesor y mejor aún, compartir controversias en un marco de respeto, a manera de retroalimentación. Por eso, la energía e idealismo potencial de los jóvenes, no pueden ser desperdiciados, sino bien canalizados hacia fines benignos, constructivos y humanos.

Por tanto, no cabe una educación abstracta y desconectada de la realidad y peor aún, carente de objetivos. Discutir en el aula las metas socio-educativas, permite trazar juntos un derrotero que dignifique al alumno como ser humano.

\section{Dimensión ética}

Arranca desde la concepción ético-filosófica institucional, en una organización axiológica, a través de los códigos de honor, estatutos, y más reglamentos. Utiliza un lenguaje doctrinal, abstracto, que innegablemente busca la objetividad como la universalidad de valores morales; para lograr una justa interacción entre las partes. Brinda espacio al diálogo, desarrolla el razonamiento moral y analiza casos de discusión. El lenguaje adquiere una función perceptiva. No obstante, si bien ha marcado directrices de actuación moral y ética para los alumnos, queda por fuera el elemento formativo esencial de todo lo que esto involucra. En consecuencia, el educa- dor debe entender su misión de transmitir la ética en el aula, a través de un ejemplo que implique su ecuánime discernimiento.

Philippe Meirieu evoca esta misión ética, y declara: “...llamaremos 'pedagogo' a un educador que tenga como fin la emancipación de las personas que le han sido confiadas, la formación progresiva de su capacidad de decidir por ellos mismos su propia historia, y que pretende conseguirlo mediante determinados aprendizajes". 37 Como antítesis a esta definición, el mismo autor con aire misterioso aunque real, rumora que esta profesión 'se encuentra bajo sospecha' pues puede existir un deseo oculto de poder, que pre-

\section{El educando está llamado a involu- crarse, así como 'insertarse', para tener derecho de poner en duda las opiniones de su propio profesor y mejor aún, com- partir controversias en un marco de res- peto, a manera de retroalimentación.}

tende manipular a otros bajo un régimen demagógico y, por lo tanto dudoso, peligroso y perverso, desencadenado por sus deseos de venganza, que se vincula a sus propias experiencias negativas con padres y maestros. Meirieu no pone en duda la calidad humana de quien educa, pero evidencia su fragilidad ética que reclama un auto-examen constante, al estar expuesto a situaciones que puedan ser críticas, y al estar en juego la formación de muchos seres humanos, y nos recuerda que "...nada es más ético que el preservar las condiciones del compromiso ético...."38 Aquí está la realización verdadera del profesor, porque entregarse al facilismo no brindaría la satisfacción plena que da el genuino deber.

Esta es la respuesta a una llamada que exige un compromiso vital. Equivale a la vocación de aprender, con dicha, sin descanso -como seres inacabados que somos-. Vocación de crear 
juntos, fusionados a la inclinación natural del educando, ávido de explorar, de vivenciar, de pensar...y el maestro confía y tiene como dice Freire, "...fe en su vocación a ser más, que no es privilegio de algunos, sino definición de los hombres". 39

Este es el testimonio de la 'educabilidad', dentro de una sana convivencia con ese potencial que cada alumno abriga, mientras que la complacencia podría indicar desinterés y hasta desprecio. Meirieu enfatiza: "La exigencia ética es, a la vez, la piedra angular y el eje central de lo pedagógico,...", 40 aunque también a veces se advierta, lo que él mismo manifiesta, “...toda actividad pedagógica se sitúa permanentemente entre la nostalgia de lo maravilloso y la tolerancia de la mediocridad". ${ }^{1}$ Sin embargo el ser humano tiene un deseo intrínseco de crecer, de perfeccionarse. Pero se encuentra ante su realidad imperfecta, proclive a la falibilidad. 'Error' sinónimo de fracaso, por ello hay dos clases de personas; 'los triunfadores y los que nunca han fracasado', como lo decretan Robert J. Kriegel y Louis Patler en su bestseller dedicado a los negocios. La clave está en no detenerse. Al respecto, Postman se atreve a contradecir el aforismo más famoso de John Dewey, "aprendemos haciendo", para expresar ahora, "aprendemos equivocándonos"; 42 es decir, por medio del ensayo-error, en una seguidilla de faltas y correcciones a las mismas. Saber que todos fallamos nos pone de cara a la humildad y a la vez nos asegura que ese constante caer y levantar, nos mantendrá vivos y atentos para no ser doblegados por la obsolescencia. Igualmente, nuestro audaz Postman, insinúa para que el educador, en una secuencia de actos valientes, se entregue como 'carne de cañón' a su alumno y enfrente ser refutado por cualquiera de sus lapsus cometidos. Es tal la fuerza de la autocrítica que propone, que incluso podría sugerir al estudiantado, como ejercicio, analizar la Constitución de su país, para corregir sus inexactitudes.

Por último, es equivocado pensar que el error está en la contradicción a 'una verdad', pues hay muchas verdades y el educando debe tener acceso a más de una verdad profunda. Yerra gravemente, el que educa y pretende imponer 'verdades' pre-establecidas. Por ejemplo, en el caso de dos verdades contrarias, se puede mantener la validez y utilidad de ambas, lo que forja tolerancia y apertura, es decir, libertad. Lo contrario sería la esclavitud a una sola verdad que derivaría hacia la hegemonía del fanatismo.

Así, para hacernos eco de estas palabras que nos animan a seguir en esta búsqueda, en el auto-conocimiento, en esta construcción co-creativa de sencillos 'saberes', con desparpajo que entraña algo de rebeldía y con la idealización que denuncia placer, irreverentemente propongo a los dictados científicos, una dimensión que la he llamado 'extra-oficial'.

\section{Una dimensión extra-oficial}

Más allá de cualquier dimensión, los actuales maestros que entienden la educación como un arte, desafían los avatares de su contexto con el ingrediente esencial del amor. Un amor sin medida, como proclama el antiguo proverbio. Un amor que en educación cobra significado porque es desinteresado, porque de lo contrario sería sólo un disfraz. Este amor se refleja en el diálogo, que es 'camino indispensable' así calificado por Jaspers. Y en este encuentro, el diálogo prende el amor y se hace luz, llama;

“...la llama es 'la parte más sutil del fuego, que se eleva y levanta a lo alto en figura piramidal. El fuego original y primordial, la sexualidad, levanta la llama roja del erotismo y ésta, a su vez sostiene y alza otra llama, azul y trémula: la del amor. ${ }^{43}$ Erotismo y amor: la llama doble de la vida". ${ }^{4}$

El acto educativo cargado de sorpresas y evidencias, podría compararse a un acto erótico por la sensualidad de su movimiento fluctuante, que toma variadas formas. Cuando hay un auténtico aprendizaje, hay seducción, encanto, que se transforma en erotismo. Esta experiencia penetra en busca del alma, se hace carne, se aprehende y se apropia del ser. Educador y edu- 
cando emprenden esta relación sagrada y se reflejan el uno al otro como espejo. En esa posición se crea el 'diálogo horizontal' como lo puntualiza Freire, que se nutre del amor y de la plena convicción de saberse semejantes y de entender definitivamente que el desarrollo y el bien del 'Otro', es el propio.

El diálogo se inicia en pequeños núcleos sociales como la escuela y la familia. Tal es el caso de Paulo Freire que creció en la 'escuela del diálogo' como él llamó a su hogar, ya que entre su madre católica y su padre espiritista, existía el máximo respeto. En este vínculo tan cercano como cotidiano, el diálogo se concibe en la matriz del amor que genera fe y esperanza en el 'Otro'. A través del diálogo se entabla una auténtica comunicación y una relación de empatía, al reconocerse que ambos están en igualdad de condiciones, que no son otra cosa que las propias características humanas.

Dentro de la dimensión comunicativa entre educador y educando, el amor destruye la relación de poder y el diálogo recurre a la palabra como el incondicional amigo. En este punto es importante identificar la condición sine qua non de escuchar la expresión de la libertad ajena. He ahí la razón para propiciar una "...Educación que lo coloque en diálogo constante con el otro..." 45 Leer, por ejemplo, es una faena crítica y creadora, un diálogo entre el autor y el lector, que produce el pensamiento reflexivo. Esta es la llave que abre la puerta del diálogo auténtico, cuando la reflexión se ha hecho íntima.

El diálogo brinda al alumno una formación progresiva, eminentemente ética, pues según Meirieu, la ética no existe de entrada y es una exigencia muy difícil. El deseo de enseñar es in- tencional y tiene fe en la 'educabilidad' del 'Otro'; $y$, a su vez, cuando quiero aprender, siento la confianza que tiene el otro (el maestro) en 'Mí'. Este equilibrio se demuestra cuando el alumno se encuentra a sí mismo, da sus propios pasos y traduce a la práctica lo que aprehende. El maestro educa con autonomía y está consciente que "Ser autónomo es querer que los demás también lo sean". $46 \mathrm{La}$ 'emancipación', cuyo antónimo "violencia ciega", 47 así contrastado por Meirieu, que infiere el 'asistencialismo' de Freire, es la llamada tanto a la inteligencia como a la libertad del 'Otro'.

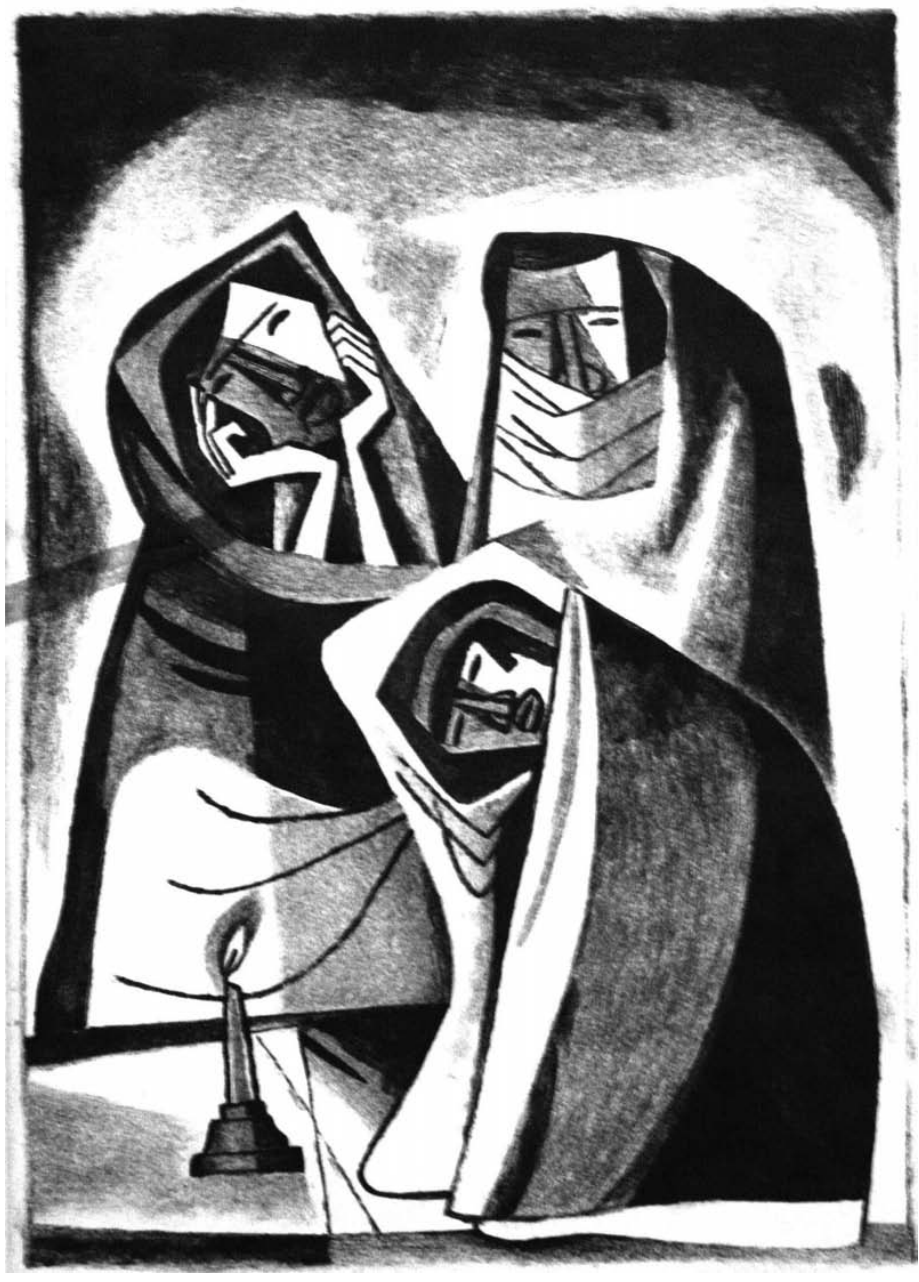

Tres mujeres. 1937 
Es importante recalcar que el educando no puede depender de un tutor, aunque éste ejerza una influencia positiva, y haya crecido una fuerte relación con él, tal como si se tratara de una intensa amistad; porque "...la mediación es, en efecto, a la vez, aquello que reúne y aquello que separa,..." $48 \mathrm{El}$ amor es independencia, autonomía, emancipación. Este nítido sentimiento no conoce la simbiosis. El maestro debe estar plenamente consciente de la llegada de sus alumnos pero más aún de la partida; semejante a la vida misma, llena de encuentros y despedidas. Por eso el maestro cuestiona, sacude, conflictúa y revoluciona el pensamiento y el alma, para plantear preguntas sin respuesta, derrumbar paradigmas y dar paso a la creación propia.

A través de la humildad el educador renuncia al protagonismo, a la razón, al absolutismo, a la imposición, al "...sentimiento de su omnipotencia y el gusto sutil de una pequeña inmortalidad..." ${ }^{49}$ Por eso, también desiste de galardones y alabanzas e incluso está dispuesto a ser censurado por la autoridad o por quienes no comprenden su misión. Más aún, como dice Meirieu, esta actitud es sabia porque evita la ceguera del orgulloso que lo aleja del propio conocimiento. $\mathrm{Al}$ respecto pienso que cuando el maestro sabe manejarse bien en su oficio, la mayor parte de las veces, no recibe reconocimiento; sin embargo, cuando algo marcha mal, suele ser sancionado. Ese es el sino del servicio; la fortuna de la humildad, que como sostiene Rabindranath Tagore, engrandece al hombre. San Agustín añadiría que cuando creemos ser humildes, hemos dejado de serlo. Sin embargo, este Santo promete que la humildad es el único camino hacia el conocimiento de la verdad. A la tarea humilde del educador, podríamos ilustrarla con este pensamiento de Miguel de Unamuno, 'El acto de más grande humildad, de verdadera humildad, es obrar' Análogamente, el maestro es la laboriosa hormiga que trabaja y construye en esfuerzo mancomunado, una pieza más del inconmensurable engranaje de la biodiversidad.

\section{Conclusión}

Hemos sido forjados a través de miles de impresiones, acontecidas en nuestra infancia y juventud, que definitivamente nos han marcado para toda la vida. El tacto, la delicadeza, la prudencia, e incluso el humor oportuno irradian un profundo respeto, haciendo la diferencia; porque las cosas se retienen en la memoria cuando son nobles y muy agradables. Las superfluas, no tardan en ser olvidadas. Por otro lado, ha habido experiencias educativas tan fuertes y negativas, que quedan como herida abierta.

Podemos entender ahora, mejor que nunca, a Postman con su mensaje: "En la medida en que no somos conscientes de hasta qué punto la forma de hablar introduce las ideas en la mente, dejamos de controlar nuestra situación" 50

Al famoso decir de Confucio, 'una gran marcha empieza por un pequeño paso'; esta disertación, no anhela ser más que unos primeros pasitos y así debemos andar y andar. Hay mucho que recorrer dentro de la sabiduría porque en verdad, nada se sabe. La fantasía de pensar que todo está dicho y hecho, nos aleja de lo certero. No obstante, estoy convencida de que el mejor camino es la humildad y la Madre Teresa de Calcuta nos recuerda en el susurrar de sus palabras, que debemos reconocer a los niños, como nuestros mejores maestros.

No podemos dejar esto a cargo de sinceros deseos. Actuar y comenzar dentro de las aulas será nuestro desafío, si huimos del ego y de los elogios, y si hablamos con honestidad para alcanzar nuestras metas. El juego debe ser lo más limpio, nada que empañe las verdades, nada que produzca ilusión ficticia y auto-engaño. Pensemos cuán trascendentes son las enseñanzas que dejamos en las aulas; ¿será que son perdurables? ¿Será que nos inspira ternura el ser humano que tenemos a cargo? ¿Lo acogemos de verdad? ¿Queremos cultivar la 'violencia ciega' y el 'asistencialismo'?

Preguntémonos también, por qué el Premio Nobel de la Paz 2006, el banquero bengalí, Muhammad Yunus declaró: "Decidí que debía re- 
nunciar a todo lo que había aprendido en las aulas para intentar simplemente ser un ser humano y buscar un modo de ser útil a otros seres humanos” ¿Será que ya 'formado', tuvo que 'aprender a desaprender'?

Debemos mirarnos una y otra vez y comprender que todos somos gestores del cambio, comandar ese poder con un sentimiento de revaloración dignificante, para apelar a la sensibilidad de los demás con nuestro ejemplo de 'ser' y 'obrar'.

Por último, quiero rendir homenaje a quiénes entienden la labor del magisterio como un ideal de servicio, y para ello acogernos a la sabi- duría de Rabindranath Tagore: 'Dormí y soñé que la vida era felicidad. Desperté y vi que la vida era servicio. Serví y descubrí que en el servicio se encuentra la felicidad'.

Es hora de despertar al imaginario del auténtico discurso educativo que forje las almas. Es oportuno mirar la utopía como una fabulosa existencia que teje la felicidad cotidiana en nuestras aulas. Es ahora que estamos para servir $¡$ sin más postergación! a la sociedad que tanto lo demanda, y junto a la Madre Teresa ser una resonancia de su inmortal frase: 'El fruto del servicio, es la paz'.

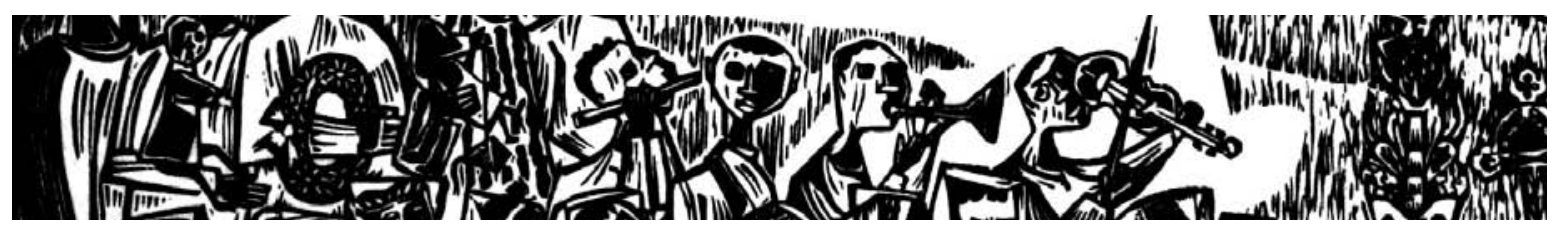

Entierro de la niña negra. Xilografía en negro y celeste. Fragmento. 1958

\section{Bibliografía}

- AEBLI, H., Una didáctica fundada en la psicología de Jean Piaget. Editorial Kapelusz, Argentina, 1973.

- ARDILA, R., Psicología del Aprendizaje. Siglo XXI editores S.A., México, 1973.

- ARROYO, J., Paulo Freire su ideología y método, Editorial Hechos y Dichos, Zaragoza, 1973.

- DAANDELS, W., Psicología del Aprendizaje (Compilación y selección de textos), Universidad Politécnica Salesiana, Quito-Ecuador.

- FREIRE, P., La educación como práctica de la libertad, Siglo XXI editores S.A., Buenos Aires, Argentina, 1975.

- GOLEMAN, D., Inteligencia Emocional, Editorial Kairós, Barcelona, 1997.

- GRIJELMO, A., La seducción de las palabras, Taurus, Madrid, 2000.

- KRIEGEL, R./ PATLER, L., Si no está roto, rómpalo, Editorial Norma, Bogotá, 1993.

- LA BIBLIA, Eclesiastés, 51.13.
- MARTÍNEZ-OTERO, V., Discurso educativo y tipología docente y dicente, Comunidad Escolar, Periódico Digital de información educativa, 11.SEP., 2002, http://comunidad escolar.pntic.mec.es/705/triburev.html

- MEIRIEU, P., La opción de educar. Ética y pedagogía, Octaedro S.L., Barcelona, 2001.

- PAZ, O., La llama doble. Amor y erotismo, Seix Barral, Barcelona, 1993.

- POSTMAN, N., El fin de la Educación. Una nueva definición del valor de la escuela, Eumo Octaedro, Barcelona, 1995.

- ROJAS, E., El hombre light. Una vida sin valores, Ediciones Temas de Hoy, Madrid, 1992.

- SÁNCHEZ, S., Pablo Freire, Una pedagogía para el adulto, Colección Lee y discute, Serie R Num. 41, Madrid, 1974.

- TRILLA, J., El legado pedagógico del siglo XX para la escuela del siglo XXI, Editorial Graó de IRIF, S.L., Barcelona, 2002. 
1 Meirieu, P., La opción de educar. Ética y pedagogía, Octaedro, S.L., Barcelona, 2001, p. 210

2 Postman, Neil., El fin de la Educación. Una nueva definición del valor de la escuela, Eumo Octaedro, Barcelona, 1995, p. 40.

3 Ibíd, p. 123 (Eclesiastés 1:18).

4 Ibíd, p. 124.

5 Postman, Neil., El fin de la Educación. Una nueva definición del valor de la escuela, Eumo Octaedro, Barcelona, 1995, p.141.

6 Expresión de Bruner, que consta en el libro - Psicología del Aprendizaje- de William Daandels.

7 Expresión de Vigotsky para identificar la fase en que el niño domina su tarea, con ayuda docente.

8 Postman, N., El fin de la Educación. Una nueva definición del valor de la escuela, Eumo Octaedro, Barcelona, 1995, p. 194.

9 Ibíd, p.141.

10 En el original "verbosa”, así traducido del portugués; que pretende referirse a verbosidad, a palabrería.

11 Expresión de Paulo Freire que infiere una caridad que esclaviza y que no educa.

12 Freire, P., La educación como práctica de la libertad, Siglo XXI Editores S.A., Buenos Aires, Argentina, 1975, p. 89.

13 Grijelmo, Á., La seducción de las palabras, Taurus, Madrid, 2000, p. 59.

14 Postman, N., El fin de la Educación. Una nueva definición del valor de la escuela, Eumo Octaedro, Barcelona, 1995, p. 133.

15 Ibíd, p. 87.

16 Ibíd, p. 210.

17 Postman, N., El fin de la Educación. Una nueva definición del valor de la escuela, Eumo Octaedro, Barcelona, 1995, p. 102.

18 Ardila, R., Psicología del Aprendizaje. Psicología y Etología, Silgo Veintiuno editores S.A., México, 1973, p. 31.

19 Postman, N., El fin de la Educación. Una nueva definición del valor de la escuela, Eumo Octaedro, Barcelona, 1995, p. 96.

20 Sánchez, S., Pablo Freire, Una pedagogía para el adulto, Colección Lee y discute, Serie R Num41, Madrid, 1974, p. 55.

21 Meirieu, P., La opción de educar. Ética y pedagogía, Octaedro, S.L., Barcelona, 2001, p. 163.

22 Expresión de Paulo Freire que se refiere a estar no 'en', sino 'con'.

23 Sánchez, S., Pablo Freire, Una pedagogía para el adulto, Colección Lee y discute, Serie R Num41, Madrid, 1974, p. 17.

24 Meirieu, P., La opción de educar. Ética y pedagogía, Octaedro S.L., Barcelona, 2001, p. 164.

25 Sánchez, S., Pablo Freire, Una pedagogía para el adulto, Colección Lee y discute, Serie R Num 41, Madrid, 1974, pág. 85

26 Aebli, H., Una didáctica fundada en la psicología de Jean Piaget, Editorial Kapelusz, Argentina, 1973, p. 16.

27 Ibíd, p. 21.

28 Ibíd, p. 28.

29 Neil Postman nombra así a la manera de contar a los alumnos nuestra historia, a la manera de cómo estamos presentando los contenidos de estudio; 'narrativa' vendría a ser el 'discurso' del que hablamos.

30 Ardila, R., Psicología del Aprendizaje. Psicología y Etología, Siglo Veintiuno editores S.A., México, 1973, p. 32.

31 Freire, P., La educación como práctica de la libertad, Siglo XXI Editores S.A., Buenos Aires, Argentina 1975, pág.92

32 Freire, P., La educación como práctica de la libertad, Siglo XXI Editores S.A., Buenos Aires, Argentina 1975, p. 29.

33 Expresión utilizada por Paulo Freire en su Pedagogía del Oprimido. 
34 Arroyo, J., Paulo Freire en Su ideología y método, Hechos y Dichos, Zaragoza, 1973, p. 27

35 Sánchez, S., Pablo Freire, Una pedagogía para el adulto, Colección Lee y discute, Serie R Num41, Madrid, 1974, p. 29 (Extraído del libro de P. Freire, Pedagogía del oprimido, p. 104).

36 Arroyo, J., Paulo Freire, Su ideología y método, Hechos y Dichos, Zaragoza, 1973, p. 23.

37 Meirieu, P., La opción de educar. Ética y pedagogía, Octaedro, S.L., Barcelona, 2001, p. 11.

38 Meirieu, P., La opción de educar. Ética y pedagogía, Octaedro, S.L., Barcelona, 2001, p. 177.

39 Arroyo, J., Paulo Freire, Su ideología y método, Hechos y Dichos, Zaragoza, 1973, p. 27.

40 Meirieu, P., La opción de educar. Ética y pedagogía, Octaedro, S.L., Barcelona, 2001, p. 175.

41 Ibíd, p. 178.

42 Postman, N., El fin de la educación. Una nueva definición del valor de la escuela, Eumo Octaedro, Barcelona, 1995, p. 136.

43 Compréndase que se refiere a ese amor asexuado dentro de una simbiosis entre profesor y alumno.

44 Paz, O., La llama doble. Amor y erotismo, Seix Barral, Barcelona, 1993, p. 7.

45 Sánchez, S., Pablo Freire, Una pedagogía para el adulto, Colección Lee y discute, Serie R Num41, Madrid, 1974, p. 85.

46 Meirieu, P., La opción de educar. Ética y pedagogía, Octaedro S.L., Barcelona, 2001, p. 165.

47 Ibíd, p. 182.

48 Ibíd, p. 124.

49 Ibíd, p. 125.

50 Postman, N., El fin de la educación. Una nueva definición del valor de la escuela, Eumo Octaedro, Barcelona, 1995, pág. 197

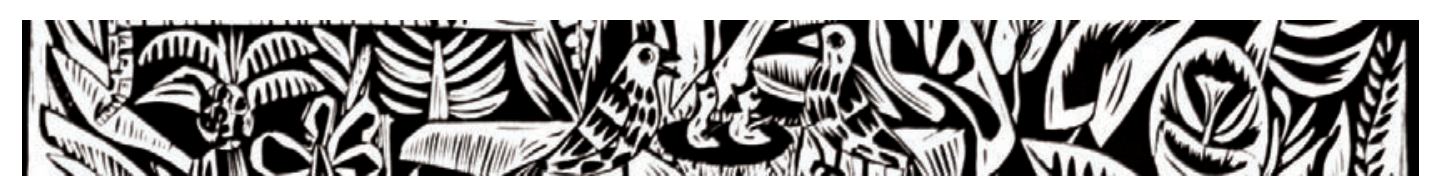

El paraíso de los cayapas. Fragmento. 1958 